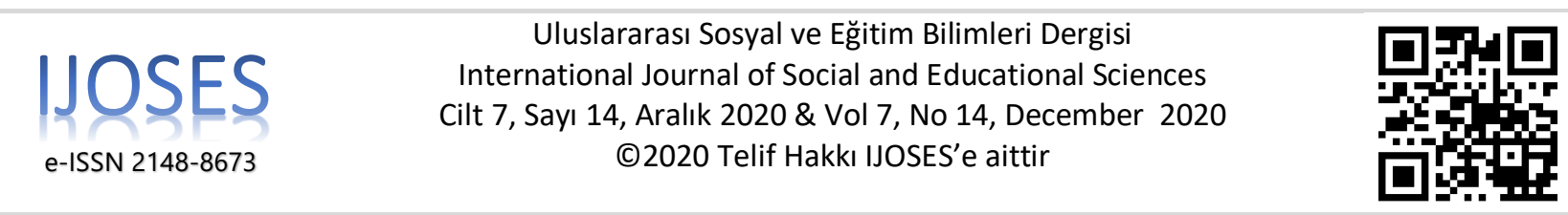

DOI: $10.20860 /$ ijoses. 799790

http://dergipark.gov.tr/ijoses

http://www.ijoses.com

Geliş Tarihi \& Received: 24.09.2020

Kabul Tarihi \& Accepted: 14.12 .2020

IJOSES, 2020, 7(14): 195-207

\title{
Google Earth'ün Sosyal Bilgiler Dersinde Başarı ve Tutumlara Etkisi
}

The Effects of Google Earth on Social Studies Course Achievement and Attitudes

\author{
Ayşe Türel Heinrichs* \& Hilmi Demirkaya **
}

\section{$\ddot{O z}$}

$\mathrm{Bu}$ çalışma, ortaokul yedinci sınıf sosyal bilgiler dersinde Google Earth kullanımının öğrencilerin başarı ve tutumları üzerindeki etkilerini belirlemek amacıyla hazırlanmıştır. Bu amaç doğrultusunda çalışma ön test-son test kontrol gruplu yarı deneysel desene uygun olarak tasarlanmıştır. 2017-2018 eğitim-öğretim yılında Antalya'da bulunan bir ortaokulda 26'sı deney, 26'sı kontrol grubunda olmak üzere 52 yedinci sınıf öğrencisinin katılımıyla gerçekleştirilen çalışmada nicel veri toplama yöntemleri kullanılmıştır. Yedinci sınıf sosyal bilgiler dersi ‘Ekonomi ve Sosyal Hayat' ünitesi, deney grubuna Google Earth kullanılarak, kontrol grubuna ise sosyal bilgiler dersi öğretim programı temelinde işlenmiştir. İşlem öncesinde ve sonrasında toplanan veriler SPSS 23.0 üzerinde hazırlanan veri tabanına işlenmiş̧ir. SPSS üzerine işlenen veriler ilişkisiz t-testi ve ilişkili t-testi teknikleri yoluyla analiz edilmiştir. İstatistiksel analizler sonucunda ortaokul yedinci sınıf sosyal bilgiler dersi ekonomi ve hayat ünitesinin öğretiminde Google Earth kullanımının öğrencilerin başarısı üzerinde anlamlı bir etkiye sahip olduğu, öğrencilerin tutumları üzerinde ise anlamlı bir etkiye sahip olmadığı tespit edilmiştir. Ortaya çıkan bu bulgular ilgili literatür ile karşılaştırıldığında bazı benzerlik ve farklılıkların olduğu belirlenmiştir. Belirlenen sonuçlar ve ilgili literatürle olan benzerlik ve farklılıklar da dikkate alınarak araştırmacı ve öğretmenlere yönelik öneriler getirilmiştir.

Anahtar Kelimeler: Sosyal Bilgiler, Google Earth, Öğretim, Başarı, Tutum.

\begin{abstract}
This study was prepared to determine the effects of using Google Earth on students' achievement and attitudes in the seventh grade social studies lesson in middle school. For this purpose, the study was designed in accordance with the semi-experimental pattern with pretest-posttest control group. Quantitative data collection methods were used in the study carried out with the participation of 52 seventh-grade students, 26 of whom were in the experimental and 26 in the control group, in a middle school in Antalya in the 2017-2018 academic year. Seventh grade social studies lesson "Economy and Social Life" unit was taught by using Google Earth to the experimental group and the social studies curriculum to the control group. The data collected before and after the transaction were entered into the database prepared on SPSS 23.0. Data processed on SPSS were analyzed through independent t-test and dependent t-test techniques. As a result of statistical analysis, it was determined that the use of Google Earth has a significant effect on students 'achievement and not a significant effect on students' attitudes in the teaching of economics and life unit of secondary school seventh grade social studies course. When these findings are compared with the related literature, it is determined that there are some similarities and differences. Considering the determined results and the similarities and differences with the related literature, suggestions were made for researchers and teachers.
\end{abstract}

Keywords: Social Studies, Google Earth, Teaching, Achievement, Attitude.

\footnotetext{
* (Yüksek Lisans Öğrencisi), Akdeniz Üniversitesi, ayshe_288@ hotmail.com, ORCID: 0000-0001-5856-6347

** (Prof. Dr.); Akdeniz Üniversitesi, hdemirkaya@akdeniz.edu.tr, ORCID: 0000-0002-4456-580X
}

Kaynak Gösterme: Heinrichs, A, T, Demirkaya, H. " Google Earth'ün Sosyal Bilgiler Dersinde Başarı ve Tutumlara Etkisi". Uluslararası Sosyal ve Eğitim Bilimleri Dergisi 7 (2020 ): 195-207. 


\section{Extended Summary}

\section{Purpose and Significance:}

In today's world, changes and developments in almost every field affect educational activities. Nowadays, when knowledge and access to information have become extremely valuable, the importance given to education has also increased (Ünal \& Demirkaya, 2019). In fact, accessing information has become much easier than before. However, the most important point is to learn information permanently. Educational institutions and educators include different methods, methods and tools in the education process for purposes such as ensuring permanent learning and increasing the effectiveness of educational activities.

Google Earth-based teaching has been integrated into classrooms since 2005. It has drawn attention that it is used extensively in the field of spatial-oriented learning experiences, especially in geography and science teaching programs. Because Google Earth allows teachers to access a large number of geographic information in a social environment (Blank, Almquist, Estrada, \& Crews, 2016).

Sheppard and Cizek (2009, p.2106) summarized the benefits of using Google Earth as follows; enjoyment and satisfaction from learning, ease of use, free, convenient and fast access to piles of pre-prepared information, placing the desired information fully into the appropriate perspective, allowing users to comprehend and develop spatial, reference or scientific knowledge in the context of local, real-life environments.

The main purpose of the research is to examine the effect of using Google Earth on student achievement and attitude in the seventh grade social studies course.

\section{Methodology:}

In this study, in which the effect of using Google Earth in social studies lesson on student achievement and attitude was examined, a pretest-posttest control group quasi-experimental design was used. This study was conducted on 52 seventh grade students studying in two different classes in a public school in Antalya province Muratpaşa district in the spring semester of the 2016-2017 academic year. 26 of the students were assigned to the experimental group and 26 to the control group.

While developing the achievement test, the table of achievement in the Social Studies Curriculum was taken into consideration. A four item multiple choice achievement test consisting of 30 questions was prepared. The resulting achievement test; sent to three domain experts. After the draft test items are written, they should be examined from various angles and their deficiencies, if any, should be eliminated (Atılgan, 2009, p. 318). Achievement test was rearranged in line with the opinions of experts. At this stage, difficulty and discrimination indexes of each question item were calculated to determine the appropriateness of the achievement test to the student level.

SPSS 23.00 statistical package program was used in the analysis of the collected data (Öztürk \& Aç11, 2020, p.59). Answers of the students who answered each question correctly were entered as "1", and empty and incorrect answers as "0". In the analysis of the pre-test and post-test scores of the experimental and control groups themselves, t-test was used for dependent groups. In the analysis between the experimental and control groups, the $t$ test was used for independent groups.

\section{Results, discussion and conclusion:}

When Table 4.2. examined, it is seen that there is no significant relationship between the experimental group's pre-test mean score $\left(\mathrm{X}^{-}=57.15\right)$ and the control group's pre-test score average $\left((\mathrm{X})^{-}=59,69\right)$. When 
Table 4.3. analyzed, it is seen that the average posttest score of the experimental group's achievement test $\left(\mathrm{X}^{-}=74.96\right)$ is higher than the posttest score average of the control group's achievement test $\left((\mathrm{X})^{-}=59.58\right)$. There is a significant relationship in favor of the experimental group between the average score of the achievement test of the experimental group and the average score of the achievement test of the control group.

When Table 4.4. analyzed, it is seen that the pretest mean score $\left(\mathrm{X}^{-}=57.15\right)$ of the achievement test of the experimental group is lower than the posttest mean score $\left(\mathrm{X}^{-}=74.96\right)$. As a result of the analysis, it can be said that there is a significant relationship between the pre-test and post-test mean scores of the experimental group in favor of the post-test mean scores, so the use of Google Earth has a positive effect on student achievement. When Table 4.5. analyzed, it is seen that the pre-test mean score $\left(\mathrm{X}^{-}=59,69\right)$ of the achievement test of the control group is higher than the post-test mean score $\left((X)^{-}=59,58\right)$. As a result of the analysis, it is understood that there is no significant relationship between the pre-test and post-test mean scores of the control group.

When the effect of Google Earth use on student achievement was examined, it was found that there was no significant difference between the pre-test scores of the students in the experimental group and the students in the control group. Özgen and Çakıcıoğlu (2009) concluded in their study that the Google Earth program enriched the quality of education and training by increasing student success with GIS software. When the effect of using Google Earth on student achievement was examined, it was found that there was a significant difference in favor of the experimental group between the post-test scores of the students in the experimental group and the students in the control group. According to the study results of Ögütveren (2014), a significant difference was found between the pre-test and post-test success scores of the experimental group students. When the effect of Google Earth use on student achievement was examined, it was found that the post-test success scores of the students in the experimental group increased significantly compared to their pre-test success scores. This situation can be interpreted as the use of Google Earth program in social studies lesson teaching increases student success. This result coincides with the findings of the study by Ögütveren (2014) on the effect of using Google Earth Program on the success of teaching 6th grade geography topics in social studies. This finding also shows similarities with the results of Merç (2017), Koçak (2013), Thankachan and Franklin (2013), Westgard (2010), Patterson (2007) and Qiu (2006).

When the effect of Google Earth use on student achievement was examined, it was found that the posttest success scores of the students in the control group did not significantly increase compared to their pretest success scores. Qualitative and quantitative studies can be conducted with social studies teachers to determine the place and importance of Google Earth program in Social studies units. 


\section{Giriş}

Yaşadığımız dünya, küreselliğin ortaya çıkmasıyla birlikte dinamik bir şekilde değişmektedir. Bu nedenle geleceğin aktif vatandaşları olacak olan öğrenciler dünyadaki bu değişimlerle başa çakabilme becerisine sahip olmalıdır. Değişim kavramının algılanması ve açıklanmasına yönelik geçici bir yaklaşımın yanında, mekan kavramı söz konusu edildiğinde coğrafya bilimindeki değişimler mekânsal bir perspektifte eşsiz bir konum kazanır (National Research Council, 2006).

Günümüz dünyasında hemen hemen her alanda yaşanan değişim ve gelişimler eğitim faaliyetlerini de etkilemektedir. Bilginin ve bilgiye ulaşmanın son derece kıymetli hale geldiği günümüzde eğitime verilen önem de artırmıştır (Ünal \& Demirkaya, 2019). Aslında bilgiye ulaşmak eskisine göre çok daha kolay hale gelmiştir. Ancak bilginin kalıcı olarak öğrenilmesi asıl önemli olan noktadır. Kalıcı öğrenmenin sağlanabilmesi, eğitim-öğretim faaliyetlerinin etkinliğini artırabilmek gibi amaçlarla eğitim kurumları ya da eğitimciler farklı yöntem ve araçları eğitim sürecine dâhil etmektedir.

Coğrafya dersi mekânı ve zamanı bir arada değerlendiren bir disiplindir. Coğrafya disiplinin konusu, insan yaşamı ile çevre arasındaki ilişki biçimlerini tespit edip ortaya koymak, bu döngüde çalışmayan noktaları belirleyerek, bunlara çözüm yolları bulmaktır. Sosyal bilgiler dersi içerisinde coğrafya konularının önemli bir yeri vardır. Öğrencilerin sosyal bilgiler dersi aldıkları yaş düzeyi göz önünde bulundurulduğunda, bilişsel gelişim açısından somut işlemler döneminde olmaları nedeniyle soyut olan coğrafya konularının ya da yerinde görülmesi mümkün olmayan mekânların sınıf ortamına taşınmasında öğretmen ve eğitim teknolojilerine önemli bir iş düşmektedir (Öğütveren, 2014, S.1).

Sosyal bilgiler dersi içerisindeki coğrafya konularının öğrenilmesi öğrencilerin örüntüleri tanımlama ve mekânsal değişim trend becerileri ile donanmış olmalarını ve değişimin neden ve sonuçlarını analiz edebilmelerini zorunlu kılar. Şöyle ki bu durum değişen toplumda daha iyi yaşamalarına ve tepkiler vermelerine yardımcı olacaktır. Bununla birlikte değişimle ilişkili mekânsal düşünme becerilerinin öğreniminin öğrenciler tarafından algılanması her zaman kolay olmamaktadır (Sawyer, Butler \& Cartis, 2011).

Geleneksel harita yöntemlerine alternatif olarak mekânsal teknolojiler öğrencileri mekânsal düşünmeye teşvik etmede olumlu bir rol oynayan araçlar olarak değerlendirilmektedir (Xiang ve Liut, 2017, s.65). Mekânsal teknolojiler kullanıcılarına yeni yöntemlerle göstermek, manipüle etmek, analiz yapmak ve sentezlemek için büyük ölçüde coğrafi bilgi sağlar (National Research Council, 2006).

Derslerde kullanılmak üzere sosyal bilgiler ve coğrafya öğretmenleri tarafindan benimsenen uygulamayı kolaylaştırıcı, güçlü görsel yeteneklere sahip ve eğlenceli etkinlik unsurlarını barındıran teknolojilerden birisi Google Earth'tür (Patterson, 2007). Geleneksel öğretime karşı Google Earth ile yapılan öğretimin en önemli üstünlügü değişim konusunda öğrencilerin mekânsal becerilerinin gelişmesine olanak sağlamasıdır (Bodzin $\& \mathrm{Fu}, 2014)$.

Google Earth temelli öğretim 2005 y1lından bu yana coğrafya ve sosyal bilgiler derslerine entegre edilmiştir. Özellikle coğrafya ve fen bilgisi dersi öğretim programlarında mekânsal amaçlı öğrenme yaşantıları alanında yoğun bir şekilde kullanıldığı dikkatleri çekmiştir. Çünkü Google Earth, öğretmenlere internet ortamında çok sayıda coğrafi bilgiye erişim imkanı sağlamaktadır (Blank, Almquist, Estrada \& Crews, 2016).

Google Earth, en popüler sanal küre yazılımıdır (Yu \& Gong, 2012, S.3970). 3D ortamında binaların görünümü Google Earth'ün en ilgi çekici başarılarındandır. Son güncellemeler ile birlikte Google Earth'de tuğlalar gerçek tuğla gibi, camlar gerçek cam gibi ve tüm dünya gerçeğine uygun bir şekilde görünmektedir (Google Corporation, 2006, S.2106). Google Earth'ün sağladığ 1 faydalar bunlarla sınırlı değildir. Sokak görünümü (Street view) sayesinde belirlenen cadde ve sokakların oradaymışçasına gezilebilmesi ya da iki nokta arasındaki mesafenin kolayca ölçülebilmesi Google Earth tarafından sunulan faydalı hizmetlerdir. 
Sheppard ve Cizek (2009, S.2106), Google Earth kullanımının sağladığı yararları şöyle özetlemiştir; öğrenmeden zevk alma ve memnuniyet, kullanım kolaylığı, önceden hazırlanmış yığınlarca bilgiye serbest, uygun ve hızlı erişim, istenilen bilgiyi tam olarak uygun perspektifin içerisine yerleştirme, kullanıcıların yerel, gerçek yaşam ortamları bağlamında mekânsal, referans ya da bilimsel bilgiyi kavrayarak geliştirmeleri.

Google Earth vasıtasıyla yapılan öğretim öğrencilerin sosyal bilgiler dersine yönelik olumlu tutum geliştirmelerine, derse katılım ve motivasyonlarını yükseltmiştir. Buradan yola çıkılarak Google Earth uygulamalarının eğitim programı mantığı ile uyumlu bütün eğitim çıktılarında kullanımı önerilebilir. Öğretmenlerin derslerinde Google Earth kullanmaları durumunda, öğrencilerin derslerde daha aktif olmalarına ve öğrendikleri teorik bilgileri pratiğe dönüştürmelerine olanak sağlanacaktır (Demirkaya, Ünal \& Çal, 2019). Bu nedenle, öğretmenler ve okul yöneticileri derslerde Google Earth gibi teknolojileri kullanmaları için okullarda gerekli ortamları oluşturmaları ve öğretmenleri desteklemelidir. Yeni teknolojilerin okullarda uygulanması konusunda karşılaşılan en önemli problemler alt yap1 sorunlarıdır. Öğretmenlerin ve okul yöneticilerinin gerekli adımları atarlarsa mevcut alt yapı sorunları da kısa sürede çözüme kavuşturulabilir (Merç ve Ersoy, 2019).

$\mathrm{Bu}$ çalışmaya Google Earth'ün sosyal bilgiler derslerinde coğrafya konularının işlenmesinde sunabileceği görsel materyaller ile zenginleştireceğinin düşünülmesi, ekonomiklik yönünden ücretsiz kullanım sunması, öğrencilerde konumsal görev yapabilme ve mekansal düşünme yeteneğini geliştirebileceğinden yola çıkılarak karar verilmiştir.

Sosyal bilgiler ve coğrafya öğretiminde mekânsal temelli eğitim teknolojilerinin öğretim başarısı ya da tutumlar üzerine etkisini inceleyen birçok çalışma yapılmıştır (Merç, 2017; Koçak, 2013; Thankachan \& Franklin, 2013; Westgard, 2010; Qiu, 2006; Kaya, 2011; Öner \& Aydın, 2014; Şengün \& Turan, 2004). Bütün bu çalışmaların sonuçları göz önünde bulundurulduğunda, Google Earth'ün ortaokul sosyal bilgiler derslerinde yer alan coğrafya konularının öğretilmesinde kullanımı, sosyal bilgiler öğretmenlerine yenilikçi teknolojileri derslerine entegre ederek, derslerini daha verimli ve zevk alarak işleyebilme olanağ sunacağ 1 öngörülmektedir. Buna ilave olarak öğrenciler açısından bakıldığında sosyal bilgiler dersinin daha sevimli ve güncel bir bakış açısıyla işlenen bir ders hüviyeti kazanacağı öngörülmektedir.

\section{Araştırmanın Amacı}

Araştırmanın temel amacı; ortaokul yedinci sınıf sosyal bilgiler dersinde Google Earth kullanımının öğrenci başarısı ve tutumu üzerindeki etkisini incelemektir.

$\mathrm{Bu}$ amaç doğrultusunda aşağıdaki sorulara cevap aranmıştır.

\section{Alt Amaçlar}

- Deney ve kontrol gruplarının ön-test başarı puanları arasında anlamlı bir farklılık var mıdır?

- Deney ve kontrol gruplarının son-test başarı puanları arasında anlamlı bir farklılık var mıdır?

- Deney grubunun ön-test ve son-test puanları arasında anlamlı bir farklılık var mıdır?

- Kontrol grubunun ön-test ve son-test puanları arasında anlamlı bir farklılık var mıdır?

- Deney ve kontrol gruplarının uygulama öncesi tutum puanları arasında anlamlı bir farklılık var midir?

- Deney ve kontrol gruplarının uygulama sonrası tutum puanları arasında anlamlı bir farklılık var midir?

- Deney grubunun uygulama öncesi ve sonrası tutum puanları arasında anlamlı bir farklılık var mıdır?

- Kontrol grubunun uygulama öncesi ve sonrası tutum puanları arasında anlamlı bir farklılık var mıdır? 


\section{Yöntem}

\section{Araştırmanın Deseni}

Sosyal bilgiler dersinde Google Earth kullanımının öğrenci başarısı ve tutumuna etkisinin incelendiği bu çalışmada, ön test-son test kontrol gruplu yarı deneysel desen (ÖSKD) kullanılmıştır. Yarı deneysel çalışmalar random atamanın yapılmadığı bununla birlikte bir eşleştirmenin söz konusu olduğu desenler yoluyla yürütülür (Fraenkel ve Wallen, 2009). Böylece katılımcılar iki gruba bölünerek deney ve kontrol gruplarına seçkisiz yolla atama yapılmaktadır. Bu nedenle çalışma grubu tasarlanırken random seçim yapılamamakta, başarı düzeyleri birbirine yakın olan sınıflar çalışma grubu olarak alınmaktadır. Böylece eğitim çalışmalarında sıklıkla başvurulan yarı deneysel desen kullanılmaktadır (Ünal, 2018).

\section{Çalışma Grubu}

Bu çalışma 2016-2017 eğitim-öğretim yılı Bahar döneminde Antalya ili Muratpaşa ilçesindeki bir devlet okulunda iki farklı sınıfta öğrenim gören 52 yedinci sınıf öğrencisi üzerinde yapılmıştır. Öğrencilerden 26's1 deney grubuna, 26's1 kontrol grubuna atanmıştır.

\section{Veri Toplama Araçları}

Çalışma verilerinin derlenmesinde başarı testi ve sosyal bilgiler dersine yönelik tutum ölçeği kullanılmıştır.

\section{Başarı Testi}

Başarı testleri, bir ünite ya da konuya başlamadan önce, eğitim-öğretim sürecinde ve ünite veya konu sonunda öğrencilerin istendik özellikleri kazanma düzeylerini ölçmeyi amaçlayan testlerdir (Metin, 2015, s.190). Başarı testi geliştirilirken Sosyal Bilgiler Dersi Öğretim Programında yeralan kazanım tablosu göz önünde bulundurulmuştur. 30 sorudan meydana gelen dört şıklı çoktan seçmeli bir başarı test hazırlanmıştır. Ortaya çıkan başarı testi; üç alan uzmanına gönderilmiştir. Taslak test maddeleri yazıldıktan sonra, çeşitli açılardan incelenerek varsa eksik yönleri ortadan kaldırılmalıdır (Atılgan, 2009, s.318). Uzmanların görüşleri doğrultusunda başarı testi yeniden düzenlenmiştir. Bu aşamada başarı testinin öğrenci düzeyine uygunluğunu belirlemek için her bir soru maddelerinin güçlük ve ayırt edicilik indeksleri hesaplanmıştır. Testte bulunan maddelerin güçlük değerleri 0.90 düzeyinde ise maddenin çok kolay olduğu, 0.20 düzeyinde ise maddenin çok zor olduğu kabul edilmektedir. Bu nedenle maddelerin güçlük indekslerinin 0.50 düzeyinde olması beklenmektedir. Madde ayırt ediciliğin 0.30 - 0.60 arasında olması, ölçme aracının başarılı ve başarısız öğrencileri birbirinden ayırdığının göstergesi olarak kabul edilir (İlhan, 2016; Sönmez ve Alacapınar, 2017). $\mathrm{Bu}$ çalışmada kullanılan madde güçlük indeksi ve madde ayırt edicilik indeksi pilot uygulama yoluyla ölçüldükten sonra zor ve çok kolay maddeler tekrar gözden geçirilmiştir.

Madde güçlük indeksi verilerinin 0.36 ile 0.90 arasında değiştiği gözlemlenmiştir. Başarı testinde yer alan bütün soruların madde ayırt edicilik indeksleri ise 0.32 ile 0.71 aralığında olduğu tespit edilmiştir. $\mathrm{Bu}$ sonuçlar başarı testinin geçerliğinin iyi düzeyde (Metin, 2015) olduğunu göstermektedir.

Hazırlanan başarı testinin güvenirliği için yapılan KR21 değeri 0.871 olarak hesaplanmıştır. Sıfır (0) veya bir (1) olarak puanlamanın yapıldığ1 testlerde kullanılan KR21 güvenirlik değeri 1'e yaklaşık olduğundan, başarı testi güvenilir (Atılgan, 2013) kabul edilmiştir. Genellikle 0.70 üzerinde bir değer almas1 başarı testinin güvenilir olduğunu açıklar (Metin, 2015, s.199).

\section{Sosyal Bilgiler Tutum Ölçeği}

Araştırmaya katılan öğrencilerin sosyal bilgiler dersine yönelik tutumlarını belirlemek amacıyla Özkal (2000) tarafından geliştirilen "Sosyal Bilgiler Tutum Ölçeği” kullanılmıştır. Tutm ölçeği olumlu ve olumsuz ifadeler içeren 31 maddeden oluşmaktadır. Ölçeğin maddeleri katılıyorum, kararsızım ve katılmıyorum seçeneklerini içeren 3'lü Likert türündedir (Akyol ve Demirkaya, 2012). Ölçeğin yapı geçerliği ve güvenirliği için İzmir ilinde bulunan üç farklı okulda öğrenim gören 214 4. ve 5. sınıf öğrencisine uygulanmıştır. Tutum 
ölçeğinin Cronbach Alpha Katsayısı 0.89 olarak tespit edilmiştir. Spearman-Brown iki yarı güvenirliği 0.88 olarak belirlenmiştir. Ölçek hoşlanma, katılma, duygu ve çalışmayı sürdürme ve isteklilik olmak üzere dört boyuttan meydana gelmektedir. Ölçeğin alt boyutlarına yönelik olarak gerçekleştirilen analiz sonucunda, Cronbach Alpha güvenirlik katsayıları hoşlanma için 0.83, katılma için 0.73, duygu için 0.76 ve çalışmayı sürdürme ve isteklilik için 0.79 olarak tespit edilmiştir. Ortaya çıkan sonuçlar bağlamında, sosyal bilgiler tutum ölçeğinin geçerli ve güvenilir olduğu kabul edilmiştir.

\section{Verilerin Toplanması}

Uygulama ve verilerin toplanabilmesi için yetkili makamlardan ve Milli Eğitim Müdürlüğü’nden gerekli izinler alınmıştır. Deney ve kontrol grubunda yer alan öğrencilere uygulama öncesinde başarı testi ve sosyal bilgiler tutum ölçeği ön test olarak uygulanmıştır. Ön test ve tutum ölçeği öğrencilere eş zamanlı olarak uygulanmıştır.

Ön test uygulamasından sonra "Ekonomi ve Sosyal Hayat" ünitesi deney grubunda araştırmacı tarafından çalışma öncesinde gerekli eğitimi yapılan Google Earth yazılımı ile desteklenerek, kontrol grubunda ise mevcut ders programı ile 03 Nisan 2017 - 05 Mayıs 2017 tarihleri arasında beş hafta boyunca dersin öğretmeni ve araştırmacı tarafından işlenmiş̧ir.

Deney grubuna Google Earth yazılımı kullanılarak, kontrol grubuna ise sosyal bilgiler dersi ögretim programına uygun biçimde işlenen uygulama süreci sonucunda her iki gruba da başarı testi ve sosyal bilgiler tutum ölçeği son test olarak tekrar uygulanmıştır.

\section{Verilerin Analizi}

Toplanan verilerin analizinde SPSS 23.00 istatistik paket programı kullanılmıştır (Öztürk ve Aç11, 2020, s.59). Her bir soruyu doğru cevaplayan öğrencilerin yanıtları ' 1 ', boş ve yanlış cevaplar ise '0' şeklinde girilmiştir. Deney ve kontrol gruplarının kendi içindeki ön test ve son test puanlarına ait çözümlemelerde bağımlı gruplar için t testi kullanılmıştır. Deney ve kontrol grupları arasındaki analizlerde ise bağımsız gruplar için t testi kullanılmıştır.

\section{Bulgular}

Deney ve kontrol grubuna ait veriler analiz edilmeden önce verilerin normallik değerleri incelenmiştir. Deney ve kontrol grubunun ön test ve son test puanlarının normallik testine ait verileri şu şekildedir.

Tablo 1. Deney ve kontrol gruplarının başarı testine ilişkin normallik değerleri

\begin{tabular}{ccccc}
\hline Testler & Gruplar & Shapiro- Wilk & Skewness & Kurtosis \\
\hline \multirow{2}{*}{ Ön test } & Deney &, 504 &,- 125 &,- 797 \\
& Kontrol &, 144 &,- 621 &, 270 \\
\hline \multirow{2}{*}{ Son test } & Deney &, 080 &,- 425 &,- 967 \\
& Kontrol &, 032 &,- 664 &,- 557 \\
\hline
\end{tabular}

Tablo 4.1 incelendiğinde çarpıklık ve basıklık katsayılarının $+1,5$ ile $-1,5$ aralığında olması verilerin normallik değerlerini sağladığını göstermektedir (Tabachnick ve Fidell, 2015). Ayrıca Shapiro- Wilk değerlerinin 0,05 düzeyinde anlamlı olmadığ yani verilerin normal dağıldığı görülmektedir ( $\mathrm{p}>0.05)$.

\section{Birinci Alt Probleme İlişkin Bulgular}

Deney ve kontrol gruplarının ön-test puanları arasında anlamlı bir ilişkinin olup olmadığını incelemek amacıyla bağımsız örneklem grupları için t-testi yapılmıştır. Yapılan analize ait bilgiler şu şekildedir. 
Tablo 2. Deney ve kontrol gruplarının ön test puanlarına ilişkin bağımsız örneklem t-Testi

\begin{tabular}{lllllll}
\hline Gruplar & $\mathbf{N}$ & $\overline{\boldsymbol{X}}$ & $\mathbf{S}$ & $\mathbf{S d}$ & $\mathbf{t}$ & $\mathbf{p}$ \\
\hline Deney & 26 & 57,15 & 22,97 & 50 &,- 446 &, 658 \\
Kontrol & 26 & 59,69 & 17,76 & & & \\
\hline
\end{tabular}

*p $>0.05$

Tablo 4.2. incelendiğinde deney grubunun başarı testine ait ön test puan ortalaması ile $(\bar{X}=57,15)$ kontrol grubunun başarı testine ait ön test puan ortalaması $(\bar{X}=59,69)$ arasında anlamlı bir ilişkinin olmadığı görülmektedir.

\section{2. İkinci Alt Probleme İlişkin Bulgular}

Deney ve kontrol gruplarının son test başarı puanları arasında anlamlı bir ilişkinin olup olmadığını incelemek amacıyla bağımsız örneklem grupları içi t-testi analizi yapılmıştır. Yapılan analize ait bilgiler şu şekildedir.

Tablo 3. Deney ve kontrol gruplarının son test başarı puanlarına ilişkin bağımsız örneklem t-Testi

\begin{tabular}{ccccccc}
\hline Gruplar & N & $\overline{\boldsymbol{X}}$ & $\mathbf{S}$ & $\mathbf{s d}$ & $\mathbf{t}$ & $\mathbf{p}$ \\
\hline Deney & 26 & 74,96 & 18,95 & 50 & 2,780 &, 008 \\
Kontrol & 26 & 59,58 & 20,92 & & & \\
\hline *p $<0.05$ & & & & & &
\end{tabular}

Tablo 4.3. incelendiğinde deney grubunun başarı testine ait son test puan ortalamasının $(\bar{X}=74,96)$ kontrol grubunun başarı testine ait son test puan ortalamasından $(\bar{X}=59,58)$ daha yüksek olduğu görülmektedir. Deney grubunun başarı testine ait puan ortalaması ile kontrol grubunun başarı testine ait puan ortalamaları arasında deney grubu lehine anlamlı bir ilişki vardır.

\section{3. Üçüncü Alt Probleme İlişsin Bulgular}

Deney grubunda yer alan öğrencilerin ön test ve son test başarı puanları arasında anlamlı bir ilişkinin olup olmadığını incelemek amacıyla bağımlı örneklem grupları içi t testi yapılmıştır. Yapılan analize ait bilgiler şu şekildedir.

Tablo 4. Deney grubunun ön test- son test başarı testi puanlarına ilişkin bağımlı t-Testi sonuçları

\begin{tabular}{rcccccc}
\hline Testler & N & $\overline{\boldsymbol{X}}$ & $\mathbf{S}$ & sd & $\mathbf{t}$ & $\mathbf{p}$ \\
\hline Ön test & 26 & 57,15 & 22,97 & & & \\
Son test & 26 & 74,96 & 18,95 & & $-9,326$ &, 000 \\
*p $<0.05$ & & & & & &
\end{tabular}

Tablo 4.4. incelendiğinde deney grubunun başarı testine ait ön test puan ortalamasının $(\bar{X}=57,15)$ son test puan ortalamasından $(\bar{X}=74,96)$ düşük olduğu görülmektedir. Yapılan analiz sonucunda deney grubunun ön test ve son test puan ortalamaları arasında son test puan ortalamaları lehine anlamlı bir ilişkinin olduğu, dolayısıyla Google Earth kullanımının öğrenci başarıları üzerinde olumlu etkisinin olduğu söylenebilir. 


\section{Dördüncü Alt Probleme İlişkin Bulgular}

Kontrol grubunda yer alan öğrencilerin ön-test ve son-test puanları arasında anlamlı bir ilişkinin olup olmadığını incelemek amacıyla bağımlı örneklem grupları içi t-testi analizi yapılmıştır. Yapılan analize ait bilgiler şu şekildedir.

Tablo 5. Kontrol grubunun ön test - son test başarı testi puanlarına ilişkin bağımlı t-Testi

\begin{tabular}{ccccccc}
\hline Testler & $\mathbf{N}$ & $\overline{\boldsymbol{X}}$ & $\mathbf{S}$ & $\mathbf{s d}$ & $\mathbf{t}$ & $\mathbf{p}$ \\
\hline Ön test & 26 & 59,69 & 17,76 & & & \\
Son test & 26 & 59,58 & 20,92 & 25 &, 040 &, 968 \\
\hline
\end{tabular}

$* \mathrm{p}>0.05$

Tablo 4.5. incelendiğinde kontrol grubunun başarı testine ait ön-test puan ortalamasının $(\bar{X}=59,69)$ son test puan ortalamasından $(\bar{X}=59,58)$ yüksek olduğu görülmektedir. Yapılan analiz sonucunda kontrol grubunun ön-test ve son-test puan ortalamaları arasında anlamlı bir ilişkinin olmadığı anlaşılmaktadır.

\section{Beşinci Alt Probleme İliş kin Bulgular}

Deney ve kontrol gruplarının tutum ölçeği ön uygulama puanları arasında anlamlı bir ilişkinin olup olmadığını incelemek amacıyla bağımsız örneklem grupları için t-testi yapılmıştır. Yapılan analize ait bilgiler şu şekildedir.

Tablo 6. Deney ve kontrol gruplarının tutum ölçeği ön uygulama puanlarına iliş kin bağımsız örneklem t-Testi

\begin{tabular}{lllllll}
\hline Gruplar & $\mathbf{N}$ & $\overline{\boldsymbol{X}}$ & $\mathbf{S}$ & $\mathbf{S d}$ & $\mathbf{t}$ & $\mathbf{p}$ \\
\hline Deney & 26 & 89,12 & 8,59 & 50 &,- 658 &, 513 \\
Kontrol & 26 & 90,96 & 11,42 & & & \\
\hline
\end{tabular}

$* \mathrm{p}>0.05$

Tablo 4.6. incelendiğinde deney grubunun tutum ölçeği ön uygulama puan ortalaması ile $(\bar{X}=89,12)$ kontrol grubunun tutum ölçeği ön uygulama puan ortalaması $(\bar{X}=90,96)$ arasında anlamlı bir ilişkinin olmadığ1 görülmektedir.

\section{Altıncı Alt Probleme İlişkin Bulgular}

Deney ve kontrol gruplarının tutum ölçeği uygulama sonrası puanları arasında anlamlı bir ilişkinin olup olmadığını incelemek amacıyla bağımsız örneklem grupları için t-testi yapılmıştır. Yapılan analize ait bilgiler şu şekildedir.

Tablo 7. Deney ve kontrol gruplarının tutum ölçeği uygulama sonrası puanlarına ilişkin bağımsız örneklem t-Testi

\begin{tabular}{lllllll}
\hline Gruplar & N & $\overline{\boldsymbol{X}}$ & $\mathbf{S}$ & $\mathbf{S d}$ & $\mathbf{t}$ & $\mathbf{p}$ \\
\hline Deney & 26 & 92,46 & 7,45 & 50 & 1,317 &, 194 \\
Kontrol & 26 & 89,27 & 9,87 & & & \\
\hline
\end{tabular}

$* \mathrm{p}>0.05$ 
Tablo 4.7. incelendiğinde deney grubunun tutum ölçeği uygulama sonrası puan ortalaması ile $(\bar{X}=$ $92,46)$ kontrol grubunun tutum ölçeği uygulama sonrası puan ortalaması $(\bar{X}=89,27)$ arasında anlamlı bir ilişkinin olmadığ görülmektedir.

\section{Yedinci Alt Probleme İliş kin Bulgular}

Deney grubunda yer alan öğrencilerin uygulama öncesi ve sonrası tutum puanları arasında anlamlı bir ilişkinin olup olmadığını incelemek amacıyla bağımlı örneklem grupları içi t-testi yapılmıştır. Yapılan analize ait bilgiler şu şekildedir.

Tablo 8. Deney grubunun uygulama öncesi ve sonrası tutum puanlarına ilişkin bağımlı t-Testi sonuçları

\begin{tabular}{ccccccc}
\hline Testler & $\mathbf{N}$ & $\overline{\boldsymbol{X}}$ & $\mathbf{S}$ & $\mathbf{s d}$ & $\mathbf{t}$ & $\mathbf{p}$ \\
\hline Ön-tutum & 26 & 89,12 & 8,59 & & & \\
Son-tutum & 26 & 92,16 & 7,45 & 25 & $-1,391$ &, 177 \\
$* \mathrm{p}>0.05$ & & & & & &
\end{tabular}

Tablo 4.8. incelendiğinde deney grubunun uygulama öncesi tutum puan ortalamasının $(\bar{X}=89,12)$ uygulama sonrası tutum puan ortalamasından $(\bar{X}=92,16)$ düşük olduğu görülmektedir. Bununla birlikte, yapılan analiz sonucunda deney grubunun uygulama öncesi ve sonrasi tutum puan ortalamaları arasında anlamlı bir ilişkinin olmadığı, dolayısıyla Google Earth kullanımının öğrenci tutumları üzerinde anlamlı etkisinin olmadığı söylenebilir.

\section{Sekizinci Alt Probleme İlişkin Bulgular}

Kontrol grubunda yer alan öğrencilerin uygulama öncesi ve sonrası tutum puanları arasında anlamlı bir ilişkinin olup olmadığını incelemek amacıyla bağımlı örneklem grupları içi t-testi yapılmıştır. Yapılan analize ait bilgiler şu şekildedir.

Tablo 9. Kontrol grubunun uygulama öncesi ve sonrası tutum puanlarına ilişkin bağımlı t-Testi sonuçları

\begin{tabular}{ccccccc}
\hline Testler & $\mathbf{N}$ & $\overline{\boldsymbol{X}}$ & $\mathbf{S}$ & sd & t & $\mathbf{p}$ \\
\hline Ön-tutum & 26 & 90,96 & 11,42 & & & \\
Son-tutum & 26 & 89,27 & 9,87 & 25 &, 725 &, 475 \\
\hline
\end{tabular}

$* \mathrm{p}>0.05$

Tablo 4.9. incelendiğinde kontrol grubunun uygulama öncesi tutum puan ortalamasının $(\bar{X}=90,96)$ uygulama sonrası tutum puan ortalamasından $(\bar{X}=89,27)$ yüksek olduğu görülmektedir. Bununla birlikte, yapılan analiz sonucunda kontrol grubunun uygulama öncesi ve sonrası tutum puan ortalamaları arasında anlamlı bir ilişkinin olmadığ söylenebilir. 


\section{Tartışma}

Sosyal bilgiler dersinde Google Earth kullanılarak elde edilen veriler nicel araştırma yöntemleri yoluyla derlenmiş ve SPSS yardımıyla analiz edilmiştir. Verilerin derlenmesinde araştırmacı tarafindan geliştirilen başarı testi ve Özkal (2000) tarafindan geliştirilen tutum ölçeği kullanılmıştır. Verilerin çözümlenmesi ile ortaya çıkan sonuçlar ve bu sonuçlarla ilgili tartışmalar şöyledir:

Google Earth kullanımının öğrenci başarısı üzerine etkisi incelendiğinde, deney grubunda yer alan öğrenciler ile kontrol grubunda yer alan öğrencilerin başarı testine ait ön-test puanları arasında anlamlı bir farkın bulunmadığı saptanmıştır. Özgen ve Çakıcıoğlu (2009)'nun çalışmalarında Google Earth programının, CBS yazılımlarının öğrenci başarısını arttırarak eğitim ve öğretim kalitesini zenginleştirdiği sonucuna ulaşılmıştır.

Google Earth kullanımının öğrenci başarısı üzerine etkisi incelendiğinde, deney grubunda yer alan öğrenciler ile kontrol grubunda yer alan öğrencilerin başarı testine ait son-test puanları arasında deney grubu lehine anlamlı bir farkın olduğu ortaya çıkmıştır. Öğütveren (2014)'in çalışma sonuçlarına göre deney grubu öğrencilerinin ön test ve son test başarı puanları arasına anlamlı bir farklılık olduğu saptanmıştır.

Google Earth kullanımının öğrenci başarısı üzerine etkisi incelendiğinde, deney grubunda yer alan öğrencilerin son-test başarı puanlarının ön-test başarı puanlarına göre anlamlı bir şekilde arttığı saptanmıştır. $\mathrm{Bu}$ durum sosyal bilgiler dersi öğretiminde Google Earth programı kullanımının öğrenci başarısını artırdığ şeklinde de yorumlanabilir. Ortaya çıkan bu sonuç, Öğütveren (2014) tarafından sosyal bilgiler 6. Sınıf coğrafya konularının öğretiminde Google Earth Programı kullanımının başarıya etkisi ile ilgili çalışmanın bulguları ile örtüşmektedir. Bu bulgu aynı zamanda Merç (2017), Koçak (2013), Thankachan ve Franklin (2013), Westgard (2010), Patterson (2007) ve Qiu'nun (2006) çalışmalarında ulaştıkları sonuçlarla da benzerlikler göstermektedir.

Google Earth kullanımının öğrenci başarısı üzerine etkisi incelendiğinde, kontrol grubunda yer alan öğrencilerin son-test başarı puanlarının ön-test başarı puanlarına göre anlamlı bir şekilde artmadığ saptanmıştır. Deney grubunda yer alan öğrencilerin tutum ölçeği ön-uygulama puanları ile kontrol grubunda yer alan öğrencilerin tutum ölçeği ön-uygulama puanları arasında anlamlı bir ilişkinin olmadığı sonucuna ulaşılmıştır.

Deney grubunda yer alan öğrencilerin uygulama sonrası tutum ölçeği puanları ile kontrol grubunda yer alan öğrencilerin uygulama sonrası tutum ölçeği puanları arasında anlamlı bir ilişkinin olmadığı sonucuna ulaşılmıştır. Deney grubunda yer alan öğrencilerin deneysel işlem öncesi tutum puanları ile deneysel işlem sonrası tutum puanları arasında anlamlı bir ilişkinin ortaya çıkmadığı sonucuna ulaşılmıştır.

Kontrol grubunda yer alan öğrencilerin uygulama öncesi tutum puanları ile uygulama sonrası tutum puanları arasında anlamlı bir ilişkinin olmadığı saptanmıştır. Bu bulguda ulaşılan sonuç Koçak'ın (2013) çalışmasıyla benzerlik göstermektedir. Kaya (2011), Öner ve Aydın (2014) çalışmalarında teknolojinin kullanımının öğrencilerin motivasyonunu arttırdığını öne sürmüşlerdir. Ayrıca Şengün ve Turan'ın (2004) çalışmalarında öğrencilerin derslerin bilgisayar desteği ile yapıldığında kalıcı öğrenmenin gerçekleştiği sonucuna ulaşılmıştır.

$\mathrm{Bu}$ araştırmadan elde edilen bulgular ve ortaya çıkan sonuçlar dikkate alınarak araştırma ile ilgili öneriler aşağıda belirtilmiştir:

Google Earth programının sosyal bilgiler eğitiminde etkili olarak kullanılabilmesi için öncelikle eğitim fakültelerinde eğitim öğretim gören öğretmen adaylarının programa ilişkin eğitim görmesi gerekmektedir. Aynı zamanda Milli Eğitim Bakanlığı bünyesinde görev yapan öğretmenlere Google Earth programının kullanımına ilişkin hizmet içi eğitim verilebilir. Google Earth programının sosyal bilgiler ünitelerinde yerini ve önemini belirlemeye yönelik sosyal bilgiler öğretmenleriyle nitel ve nicel çalışmalar yapılabilir. Google Earth programı kullanılırken kullanıcının (öğretmenin) yeni veriler üreterek programın kendi menülerine sıkışan standart kalıbından kurtarılabilir. Sosyal bilgiler öğretmenlerinin Google Earth programının kullanımında kendilerini yetersiz hissetmelerinin nedenlerini araştırarak bu konuda çözümler üretilmelidir. 


\section{Kaynakça}

Akyol, Ş., \& Demirkaya, H. (2012). Determining prospective teachers' styles of goal accomplishment. Mediterranean Journal of Humanities, II(2), 17-24.

Atılgan, H. (2009). Test geliştirme. H. Atılgan (Edt.). Eğitimde Ölçme ve Değerlendirme içinde (s. 315-348). Ankara: Anı Yayıncılık.

Atılgan, H. (2013). Eğitimde ölçme ve değerlendirme (6. Baskı). Ankara: Anı Yayıncılık.

Blank, L. M., Almquist, H., Estrada, J. \& Crews, J. (2016). Factors affecting student success with a Google Earth-based earth science curriculum. Journal of Science Education and Technology, 25, 77-90. doi: 10.1007/s10956-015-9578-0

Bodzin, A. \& Fu, Q. (2014). The effectiveness of the geospatial curriculum approach on urban middle level students' climate change understandings. Journal of Science Education and Technology, 23, 575-590.

Demirkaya, H., Ünal, O. \& Çal, Ü. T. (2019). Use of Google Earth in social studies education. In E. Koçoğlu (Ed.). Technological Reflections in Social Studies Education (pp. 131-144.)

Fraenkel, J. R. \& Wallen, N. E. (2009). How to design and evaluate research in education. New York: McGraw-Hill.

Google Corporation. (2006). Google Earth Release 4. Retrieved 10/05/2020 from http://earth.google.com/earth4.html

İlhan, M. (2016). Açık uçlu sorularla yapılan ölçmelerde klasik test kuramı ve çok yüzeyli rasch modeline göre hesaplanan yetenek kestirimlerinin karşılaştırılması. Hacettepe Üniversitesi Eğitim Fakültesi Dergisi, 31(2), 346-368.

Karasar, N. (2015). Bilimsel araştırma yöntemi. (28. Basım). Ankara: Nobel Akademik Yayıncılık Eğitim Danışmanlık Tic. Ltd. Şti.

Kaya, H. (2011). Orta öğretimde Coğrafya öğretiminde CBS'nin öğrenci başarısına etkisi. Marmara Coğrafya Dergisi, 23, 308-326.

Koçak, F. (2013). Orta öğretim Coğrafya dersinde Google Earth'ün kullanımının değerlendirilmesi. Yayınlanmamış Yüksek Lisans Tezi. Karadeniz Teknik Üniversitesi, Trabzon.

Merç, A. (2017). Sosyal bilgiler dersinde mekân algılama becerisinin kazandırılmasında Google Earth uygulamasının etkililiği. Yayınlanmamış Doktora Tezi. Anadolu Üniversitesi Eğitim Bilimleri Enstitüsü, Eskişehir.

Metin, M. (2015). Nicel veri toplama araçları. M. Metin (Edt.). Kuramdan Uygulamaya Eğitimde Bilimsel Araştırma Yöntemleri içinde (s. 161-214). Ankara: Pegem Akademi.

National Research Council (2006). Learning to think spatially: GIS as a support system in the K-12 curriculum. Washington DC: The National Academies Press.

Ögütveren, M. (2014). The influence of google Earth software on the success of teaching geographical topics for the 6th grade students. Giresun University The Institute of Social Sciences, Giresun.

Öner, S. ve Aydın, F. (2014). Coğrafi bilgi sistemleri destekli eğitimin coğrafya dersindeki akademik başarı üzerindeki etkisi. TSA, 18(3), 179-196.

Özgen, N. ve Çakıcıŏlu, R. (2009). Coğrafi bilgi sistemlerinin (CBS) coğrafya eğitiminde kullanımı ve dersin hedeflerine ulaşma düzeyine etkisi. KEFAD Kırşehir Eğitim Fakültesi Dergisi, 10(1), 81-90. 
Özkal, N. (2002). Sosyal bilgiler dersine yönelik tutum ölçeğinin geliştirilmesi. Eğitim ve Bilim, 27(124), $52-55$.

Öztürk, A., \& Açıl, F. B. (2020). Sosyal bilgiler öğretmen adaylarının üst bilişsel farkındalıklarının bazı değişkenlere göre incelenmesi. JIRSS - Journal of Innovative Research in Social Studies, 3(1), 54-69.

Patterson, T. C. (2007). Google Earth as a (not just) geography education tool. Journal of Geography, 106, $145-152$.

Qiu, K. (2006). Geographic information technologies: An influence on the spatial ability of university students. Unpublished Doctoral Dissertation. USA: Texas State University.

Sawyer, C., Butler, D. \& Cartis, M. (2011). Using webcams to show change and movement in the physical environment. Journal of Geography, 109, 251-263.

Sheppard, S. R. J. \& Cizek, P. (2009). The ethics of Google Earth: Crossing thresholds from spatial data to landscape visualisation. Journal of Environmental Management, 90(6), 2102-2117. doi: 10.1016/j.jenvman.2007.09.012

Sönmez, V. \& Alacapınar, F. G. (2017). Örneklendirilmiş bilimsel araştırma yöntemleri (5. Baskı). Ankara: Anı Yayıncilık.

Şengün, T. M., Turan, M. (2004). Coğrafya eğitiminde bilgisayar destekli ders sunumunun öğrenmedeki rolünün öğrenci görüşlerine göre değerlendirilmesi. The Turkish Online Journal of Educational Technology, 3, 93-99.

Tabachnick, B. \& Fidell, L. S. (2015). Çok değişkenli istatistiklerin kullanımı. Ankara: Nobel Akademik Yayınc1lik.

Thankachan, B. and Franklin, T. (2013). Impact of Google Earth on student learning. International Journal of Humanities and Social Science, 3(21), 11-16.

Ünal, O. (2018). Sosyal bilgiler dersinde eğitici çizgi roman kullanımının öğrenci başarısı ve tutumuna etkisi. Yayınlanmamış Yüksek Lisans Tezi. Akdeniz Üniversitesi Eğitim Bilimleri Enstitüsü, Antalya.

Ünal, O. ve Demirkaya, H. (2019). Eğitici çizgi romanın sosyal bilgiler dersinde kullanılmasına yönelik yarı deneysel bir çalışma. International Journal of Geography and Geography Education, 40, 92-108 . DOI: 10.32003/iggei.569650

Xiang, X. \& Liut, Y. (2017). Understanding change through spatial thinking using Google Earth in Secondary geography. Journal of Computer Assisted Learning, 33, 65-78.

Westgard, K. (2010). Google Earth in the middle school geography classroom: Its impact on spatial literacy and place geography understanding of students. Unpublished Doctoral Dissertation. USA: University of North Dakota.

Yıldırım, A. ve Şimşek, H. (2013). Nitel araştırma yöntemleri (9. Baskı). Ankara: Seçkin Yayıncılık.

Yu, L. \& Gong, P. (2012). Google Earth as a virtual globe tool for Earth science applications at the global scale: progress and perspectives. International Journal of Remote Sensing, 33(12), 3966-3986. 